\title{
Modern trends in teaching with the use of information technology
}

\author{
Yanina Morozova*, and Valentina Demchenko \\ Don State Technical University, 344002, Rostov-on-Don, Russia
}

\begin{abstract}
The article examines the modern trajectories of teaching a foreign language using information technology. The analysis of research by domestic and foreign scientists on the problems of optimization and choice of strategies in teaching a foreign language is given. Special attention is paid to the role of communication technologies and Internet resources in mastering speech skills and professional competencies. The characteristics of the types of Internet resources and their importance in teaching a foreign language are given.
\end{abstract}

\section{Introduction}

Globalization and modernization of education has affected various areas of modern society. This led to the growth of international contacts and the need to overcome not only linguistic, but cultural and mental barriers. The problem of organizing a foreign language educational process is quite relevant, because it requires the training of specialists who are competitive and in demand on the European and world labor markets.

For successful international cooperation, UNESCO has developed an international language program "Lingvouni", which defines modern requirements for the formation of foreign language socio-cultural competence. At the same time, the recommendations of the Council of Europe note that language training programs should be aimed at the formation of a multicultural personality, which would be:

- Speech personality (implementation of speech activity in several languages, considering the complex of psychophysiological properties of the individual);

- Communicative Personality (the ability to verbal behavior with representatives of different linguistic societies);

- Vocabulary Personality or ethnosemantic (symbiosis and integration, reflected in the lexical system of languages of value socio-cultural trends) (Common European competencies in foreign language proficiency: Study, training, assessment / Department of language policy. - Strasbourg: MSLU, 2005.-10p.)

Speaking about intercultural communication, we must bear in mind the system of guidelines necessary for the implementation of speech activity with representatives of a different culture, both in the background and in the real environment. According to A.A. Leont'ev, mastering a new language is a transition to a new image of the world, which is

\footnotetext{
* Corresponding author: morozova@mail.ru
} 
necessary for mutual understanding and cooperation with native speakers of this language [4, p.28]

\section{Materials and methods}

The analysis and generalization of scientific literature on the problem, expert assessment, methods of qualitative and quantitative processing of the data obtained, meaningful interpretation of the results and conclusions were carried out.

\section{The results}

Domestic scientists G.A. Anisimov, N.V. Baryshnikov, A.V. Vandysheva, G.I. Elizarova, O.M. Osiyanova, G.V. Terekhova and others, touching upon this problem, draw attention to the importance of linguistic education modernization and the formation of a polycultural linguistic personality, as a requirement of a new global situation [3, p.16; 11, p.192].

It should be noted, that modern trends in the language education field necessitate the formation of a new type of personality, comprehensively educated and owning selfmanagement, i.e. the ability to plan further self-education. Therefore, it is no coincidence that, since the $90 \mathrm{~s}$, the paradigm of multicultural education and upbringing has been established in European countries, as evidenced by the studies of foreign scientists: G.C.Beacco, M. Byram, G. Billier, F.C.Acarton, M. Cavalli and others [20]. The Council of Europe approved the regulation «Modern languages: learning, teaching, evaluating. «Common European Competence»"), which provides a characteristic of the level of language proficiency in accordance with international standards, and also adopted the «Program for the development of linguistic educational policies in Europe», in which bilingualism and polylinguism are considered as the acquisition of transuniversal competence in the studied languages, as a cultural aspect from polylinguistic and multicultural competence [17, p.16121; 19, p.1245]

It should be emphasized, that over the past decades, the language policy of organizations at all levels, from government to educational, both in Russia and in the West, has been focused on promoting the development of cultures and languages, on the formation of an individual's ability to use a foreign language as a tool for European cooperation, as well as for forming a common education area. This task can be achieved through specific strategies of teaching foreign languages. In a number of studies by foreign and native scientists, the concept of «strategy» of teaching a foreign language is classified differently among foreign researches, the most famous are the strategies developed by G. Rubin, R. Oxford and others. For example, G. Rubin suggests that «strategy» is a set actions used to obtain, store and use information. He identifies three types of strategies: language learning strategy, communication and social strategies $[15 ; 16]$

Language learning strategies include cognitive (perception, memorization, reproduction of foreign speech) and metacognitive (observation, planning, control) strategies.

Communication strategies are aimed at the ability to conduct a dialogue, at understanding the information received from the interlocutor or from scientific sources [14].

Social strategies are the ability to interact in a group, team.

All of the above strategies are focused on the learning goal.

The concept of «strategy» came to the interlanguage theory through comparative psycholinguistics based on the analysis of the mistakes and as special actions that help students to make the learning process easier, faster, purposeful and effective. 
In this regard, we should also pay attention to R. Oxford's research on the application of strategies. She identified two main types of strategies - direct and indirect, which, in turn, are subdivided into three types [15]. So, the types of direct strategies are shown in the Figure 1:

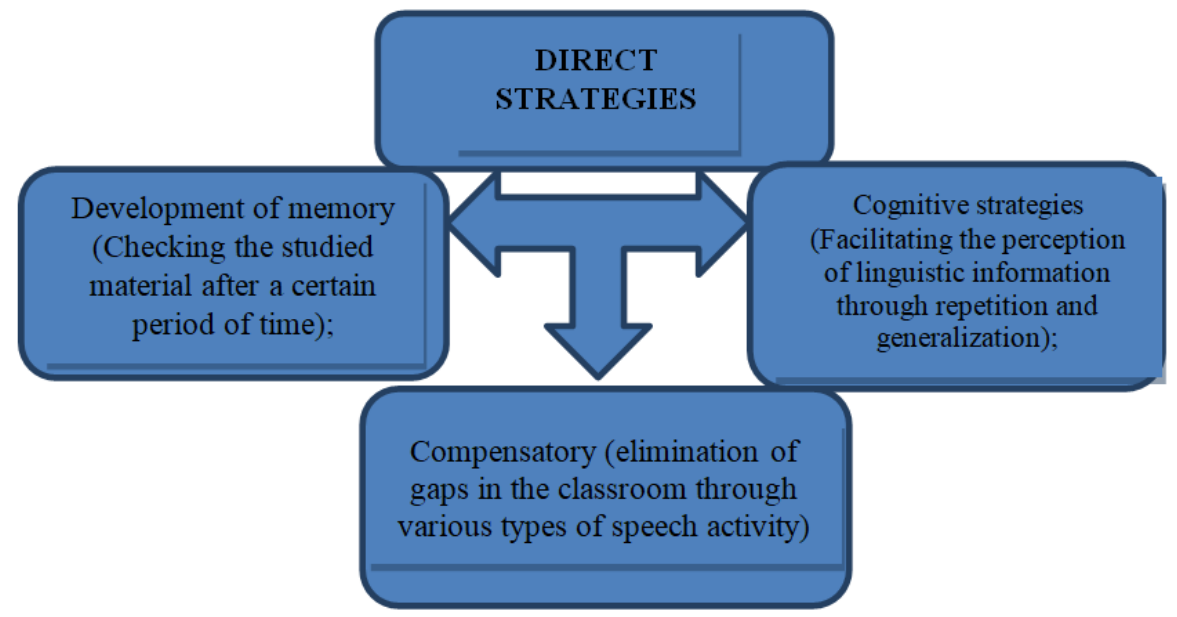

Fig. 1. The types of direct strategies

Indirect strategies involve the use of a foreign language in speech for the learning process itself and for gaining knowledge from information in a foreign language. The types of indirect strategies are shown in the Figure 2:

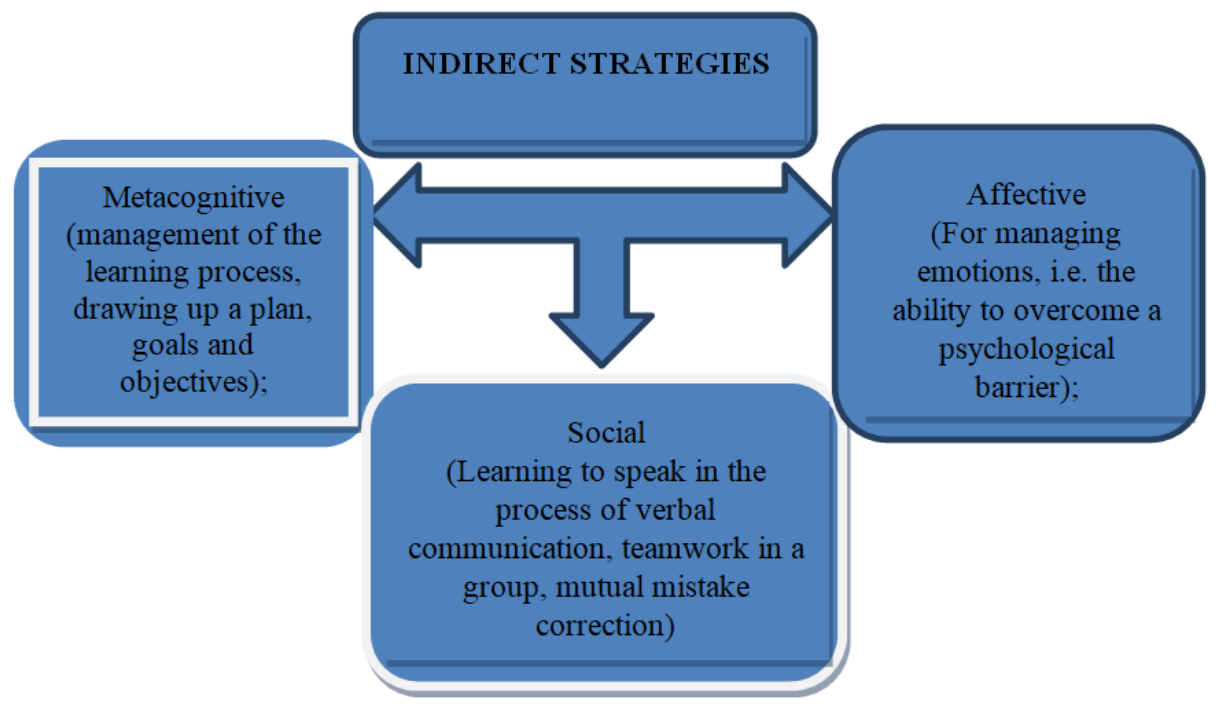

Fig. 2. The types of indirect strategies

The social demand of society, due to the expansion of economic and cultural bonds, increases the requirements for the level of language training, not only in terms of mastering practical speech communication skills, but also the ability to use a foreign language as the extraction of various information and self-education. In this regard, the creation of an interactive educational space deserves special attention, in which the process of mastering a foreign language would be the most optimal [8]. With all the opportunities presented by 
information technology, the main one is Internet communication and a personality-oriented approach in teaching a foreign language.

At the same time, the teacher needs to determine the level of students' proficiency in computer technologies, their technical capabilities to cooperate remotely, motivation in the possession of knowledge and professional communicative competencies. The most relevant modern technologies used in teaching a foreign language are shown in the Figure 3.

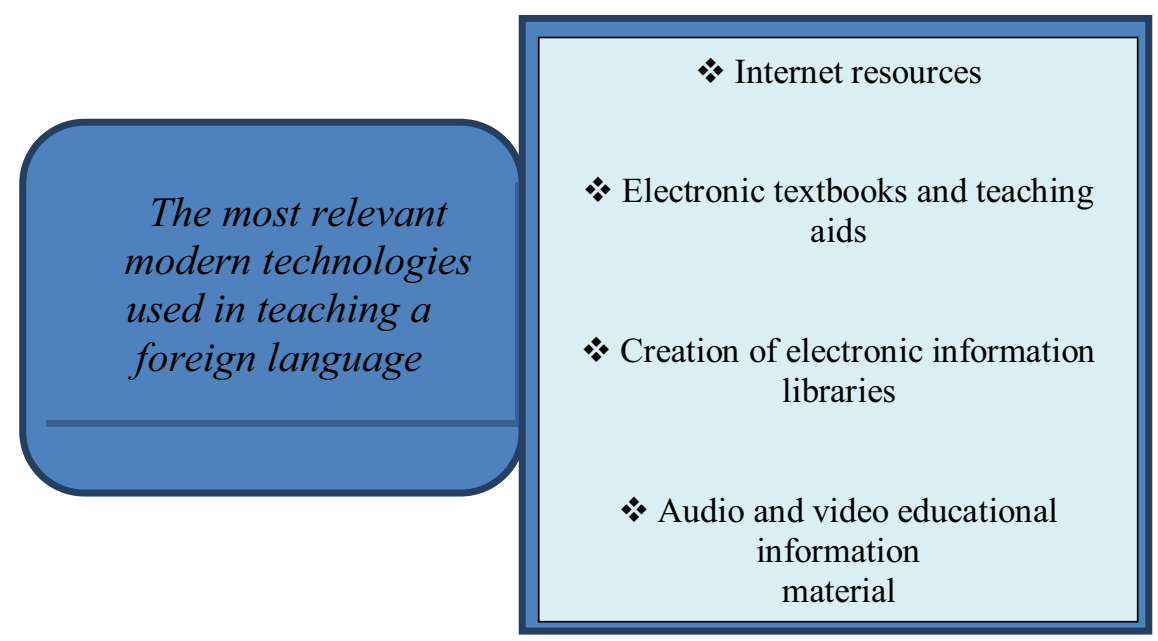

Fig. 3. The most relevant modern technologies used in teaching a foreign language

The most active form of teaching a foreign language is Internet communication, which is considered as an opportunity to form a linguistic personality based on the use of Internet resources, through which the process of self-actualization of a person is carried out. Due to the absence of a psychological barrier through the virtual nature of communication, students can more freely communicate using various speech means, and successfully interact with representatives of other cultures [6]. Currently, computer discourse is distinguished by a huge communicative orientation, which allows you to broaden the horizons of students, increase motivation, and identify potential creative opportunities for students. With the help of information technology, interactive cooperation between students and the teacher is provided, opportunities for independent work appear, as well as the improvement and control of knowledge and acquired skills [5;2].

Information and communication technologies are divided into interactive ones (maintaining a two-way dialogue between a teacher and a student). Its purpose lays in helping students to transform general information into personal knowledge and skills.

Non-interactive ones (aimed at independent, autonomous study of educational materials and resources).

The most effective is the use of various combinations of interactive and non-interactive nature. The use of interactive (communication) technologies is considered to be the most effective because it enables students to consult with the teacher, and the teacher to control the learning process.

Information and communication technologies can also be divided into two groups: asynchronous technologies, which do not require the simultaneous interaction of the participants in the dialogue; synchronous, which involves the interaction of all the participants at the same time.

\section{Discussion}


The impetus for the development of the information sphere was listening. The sounding speech began to be recorded on multimedia carriers, which later turned into podcasts (audio or video recording made by the user and available for listening or viewing on the Internet on a special video recording service) $[10 ; 12]$.

The main advantage of these messages is the ability to hear the speech of a native speaker. Another significant technique for using information technology is video-based learning. Currently, there is a huge selection of videos on the Internet for both beginners and those who continue to learn a foreign language. Due to the high effectiveness of the impact of visibility, the use of video files in the process of teaching foreign language acquires not only teaching but also educational functions. In this regard, it becomes necessary to organize specially the educational process, in which the possibility of using video in the classroom would act as an incentive for self-education and improving the quality of knowledge in a foreign language. The use of video materials in the educational process allows students to get more complete, reliable information about the phenomena studied in the language, increase motivation in learning a foreign language, more productively monitor and correct knowledge, as well as take into account the interests and creativity of students.

The main goal of information programs is to master the active colloquial vocabulary of native speakers. Most of the students and teachers prefer YouTube, where anyone can create their own channel, which will store various videos: films, tutorials, etc.

Currently, Internet users have the opportunity to use a variety of electronic textbooks, manuals, scientific literature and fiction adapted texts in the language, various forms and platforms with the help of which one can learn more deeply the language and culture. G.N. Malyukova identifies the main groups of tasks solved with the help of multimedia, which include [5]:

- Support of the educational process;

- Realization of real communication with a native speaker;

- Providing access for all participants in the educational process to information funds;

- Ensuring interaction between teachers, exchange of pedagogical experience and didactic materials

It should be noted, that multimedia programs are adapted for different levels of language proficiency and students can use them both for self-control and for expanding the lexical stock of the language. But the opportunity to hear the pronunciation of a native speaker and to pay attention to the phonetic and intonational features of the speaker stands out, which also contributes to the active assimilation of lexical-grammatical and speech structures of the language due to clarity. This group includes such programs as Microsoft World, Microsoft Power Point, Microsoft Excel. Their advantage lies in their ease of creation and capacity. The teacher can use it for specific situations, topics, work with a group with a variety of options [7].

The main goal of information programs is to master the active colloquial vocabulary of native speakers. Most of the students and teachers prefer UTube, where anyone can create their own channel, which will store various videos: films, tutorials, etc.

Currently, Internet users have the opportunity to use a variety of electronic textbooks, manuals, scientific literature and fiction adapted texts in the language, various forms and platforms with the help of which one can learn more deeply the language and culture. G.N. Malyukova identifies the main groups of tasks solved with the help of multimedia, which include:

- Support of the educational process;

- Realization of real communication with a native speaker;

- Providing access for all participants in the educational process to information funds; 
- Ensuring interaction between teachers, exchange of pedagogical experience and didactic materials

Social network is an important aspect of the use of information and communication technologies. This platform is an online service or website designed to build, reflect and organize social relationships. One of these types of social networks can be attributed to language social networks that allow you to learn a foreign language on your own. According to Y.S. Mushnikova, all language networks can be divided according to specialization, availability of information and geographic principle. Today, social media can help improve your speaking and writing skills. With their help, you can contact a person anywhere in the world and get the opportunity to learn more about both the language and the culture of the country. So, the most popular social network in Europe is Facebook. A distinctive feature of this technology is the minimum amount of time spent on language learning, where special language skills are not required. It also should be noted, that using language networks, the teacher is a coordinator, in which communication with the student will be mediated. Therefore, the main tasks of the teacher is to interest and motivate the student to the studied discipline. To a large extent, programs using the Internet are developed on the basis of the English language. Among them, such Internet resources for the development of communication and speech skills as: hotlist, multimedia scrapbook, treasure hunt, subject simple, Web quest. The most actively used Web Quest, with its help students can look for information, identify a topic or problem, present the content of what they previously read or saw, express and argue their point of view, participate in a conversation or discussion [9, p.62; 18, p.1229].

Thus, the skills necessary for receptive and productive types of speech activity, i.e. speaking, reading, listening and writing, are developed [9, p.64].

\section{Conclusion}

Undoubtedly, the use of communication technologies expands the possibilities for the quality of education. This is also evidenced by the studies of domestic methodologists: V.I.Bogolyubov, E.V. Polat, G.K. Selevko, G.A. Kitaygorodskaya, A.V. Shchepilova and a number of others. They consider the use of information technology through the prism of the introduction of innovative pedagogical technologies. Among them, one can distinguish virtual training technologies, distance learning technologies, the technology of intensive teaching a foreign language, technologies of synchronous-sound-visual training, etc. [1, p.9].

So E.S. Polat, touching upon the problem of distance learning, notes that at the center of the learning process should be the independent cognitive activity of students aimed at mastering and forming the necessary language skills and abilities, where the student must have the skills to work not only with a computer, but also ways of working with authentic information on the Internet., with electronic textbooks, dictionaries and reference books, promptly and systematically interact with the coordinating consultant (teacher) when using search methods when working on certain modules of the training course [13, p.7].

Thus, we can conclude that at present the problem of organizing a foreign language educational process is quite relevant. The modern technique is in search of optimization of teaching foreign languages, where information and communication technologies play a leading role in the development of various language projects. Distance education, the development of individual strategies and group strategies of the type of cooperation (cooperative learning) are becoming increasingly important, technologies of intensive teaching of foreign languages are being tested, in which information technologies are the main component of educational content. 


\section{References}

1. V.I. Bogolyubov, Theoretical foundations for the design of modern pedagogical technologies, PhD Thesis, 5-15 (1999).

2. E. Egorova, N. Bulankina, O. Mishutina, V. Tsybaneva, Technology for designing a digital educational course for the university students, INTED2021 Proceedings. DOI: 10.21125/inted.2021.0165 (2021)

3. G.I. Elizarova, Formation of a multicultural linguistic personality as a requirement of a new global situation 20 (2005).

4. A.A. Leontiev, Language and consciousness: paradoxical rationality, (1993).

5. G.N. Malyukova, The use of multimedia tools in teaching a foreign language, Electronic resource, htttp: //festival.1september.ru/articles/212523, last accessed 2021/03/10.

6. T. Mikheeva, E. Murugova, Y. Morozova, V. Demchenko, Training as a major tool of teacher professionalism enhancement, INTED 2020 Proceedings 14th International Technology, Education and Development Conference 1211-1215 (2020). DOI: 10.21125/inted.2020.0417.

7. J.S. Morozova, I.G. Kuzheleva, The research of personal and professional development features of college graduates in the university: content and methods», Innovative Technologies in Science and Education (ITSE-2020), (2020). DOI: https://doi.org/10.1051/e3sconf/202021022026

8. E.V. Murugova, T.B. Mikheeva, E3S Web of Conferences 210, 18095 (2020). DOI: https://doi.org/10.1051/e3sconf/202021018095.

9. Yu.S. Mushnikova, Young scientist 33, 62-63 (2017).

10. O.A. Obratneva, Application of modern information technologies in teaching a foreign language, htttp: //pskgu.ru/projects/pgu/storage/wt/t141/wt141_18.pdf,last accessed 2021/03/11.

11. O.M. Osiyanova, Bulletin of OSU 6, 191-193 (2002).

12. S.V. Pervukhina, G.I. Radchenko, E3S Web of Conferences 210, 18036 1-10 (2020). https://doi.org/10.1051/e3sconf/202021018036.

13. E.S. Polat, IYaSh 5, 6-11 (1998).

14. P.V. Sysoev, Methods of teaching a foreign language using new information and communication Internet technologies: a teaching aid for teachers, graduate students and students, 182 (2010).

15. R.L. Oxford, Language learning strategies (New-York, 1990).

16. J. Rubin, A. Wenden, Learner Strategies in Language Learning (Prentice Hall, New Jersy, 1987).

17. D. Gregory Clemenson and E.L. Craig Stark, J Neurosci, 35 (49), 16116-16125 (2015).

18. Simone Kühn, Dimitrij Tycho Kugler, Jürgen Gallinat, A longitudinal intervention study, Mol Psychiatry 24 (8), 1220-1234 (2019).

19. M. Bold, Interaction in distance learning (Encyclopedia of distance learning, NY, 2009).

20. G. Russell, The problems and possibilities of virtual schools (Encyclopedia of distance learning, NY, 2009). 